\title{
An update on the incidence of human giardiasis in Scotland, 2011-2018
}

\author{
Lynne C. Ferguson ${ }^{1 *} \mathbb{D}$, Alison Smith-Palmer ${ }^{2 \dagger}$ and Claire L. Alexander ${ }^{1 \dagger}$
}

\begin{abstract}
Background: Giardia duodenalis is one of the most common parasites in the UK to cause diarrhoeal illness. Giardiasis is likely to be significantly under-reported in the UK as laboratory testing is largely based on examining stool samples from individuals with a recent travel history. This results in the majority of locally-acquired cases going undetected. To increase awareness of giardiasis, we describe data gathered from cases reported within Scotland during 2011-2018.

Methods: All of the 21 Scottish National Health Service (NHS) diagnostic microbiology laboratories performed microscopy examination to detect Giardia cysts in stools, from mostly travel-related cases. The exception was one laboratory that implemented an antigen-based enzyme immunoassay in 2015. This resulted in every submitted stool being tested for Giardia. Laboratory-confirmed cases of giardiasis were reported to Health Protection Scotland (HPS) via the Electronic Communication of Surveillance in Scotland (ECOSS) during the eight-year period. Data for calculating the incidence per 100,000 of the population were obtained from the National Records of Scotland mid-2018 population estimates in Scotland.
\end{abstract}

Results: A total of 1631 Scottish cases were reported during 2011-2018 (8-year mean: 204; range: 166-269). National Health Service Grampian, Borders and Lothian reported the highest incidence of Giardia (9.8, 7.5 and 6.7 per 100,000, respectively), all of which were above the Scottish mean incidence (3.8 per 100,000). Following the implementation of antigen testing in NHS Grampian during 2015, reports significantly increased 3.6-fold ( $P=0.005$ ). The highest incidence of giardiasis occurred in the 20-49 years age group (mean 5.4 per 100,000). Of interest, the mean incidence of giardiasis was significantly higher in males than in females (4.8 versus 3.1 per 100,000, respectively; $P<0.0001$ ).

Conclusions: This report highlights the need to capture enhanced information on every laboratory-confirmed case of giardiasis to gain a better understanding of the local sources and transmission pathways occurring in Scotland. In addition, implementing sensitive, automated technologies across UK NHS diagnostic microbiology laboratories to permit the efficient, routine testing of every submitted stool for Giardia, should be encouraged to ensure all cases are identified and treated appropriately.

Keywords: Giardia, Scotland, Under-reporting, Incidence

\footnotetext{
*Correspondence: lynne.ferguson3@ggc.scot.nhs.uk

${ }^{\dagger}$ Alison Smith-Palmer and Claire Low Alexander contributed equally to this work

${ }^{1}$ Scottish Microbiology Reference Laboratories, Glasgow, Scotland, UK

Full list of author information is available at the end of the article
}

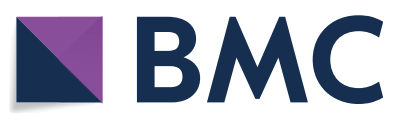

(c) The Author(s) 2020. This article is licensed under a Creative Commons Attribution 4.0 International License, which permits use, sharing, adaptation, distribution and reproduction in any medium or format, as long as you give appropriate credit to the original author(s) and the source, provide a link to the Creative Commons licence, and indicate if changes were made. The images or other third party material in this article are included in the article's Creative Commons licence, unless indicated otherwise in a credit line to the material. If material is not included in the article's Creative Commons licence and your intended use is not permitted by statutory regulation or exceeds the permitted use, you will need to obtain permission directly from the copyright holder. To view a copy of this licence, visit http://creativeco mmons.org/licenses/by/4.0/. The Creative Commons Public Domain Dedication waiver (http://creativecommons.org/publicdomain/ zero/1.0/) applies to the data made available in this article, unless otherwise stated in a credit line to the data. 


\section{Background}

Giardia duodenalis (syns Giardia intestinalis and Giardia lamblia) is a flagellated protozoan found worldwide and is one of the most common parasitic causes of gastrointestinal illness in the UK [1]. Giardiasis commonly presents as foul-smelling diarrhoea, abdominal pain, and excessive flatulence. Infection can result in long-term issues including irritable bowel syndrome (IBS) and chronic fatigue [2]. Asymptomatic carriage is also possible [3]. Of importance, giardiasis is a treatable disease requiring the administration of antimicrobial drugs such as metronidazole and tinidazole [4]. Transmission occurs via the faecaloral route through the ingestion of infective cysts. While human to human transmission occurs, zoonotic transmission remains debatable [5, 6]. Outbreaks of Giardia associated with contaminated food and water sources have been reported $[7,8]$.

Stools are submitted for Giardia testing to National Health Service (NHS) diagnostic microbiology laboratories from general practitioners (GPs) and hospital clinicians throughout Scotland. Requests are mostly received from individuals with a recent travel history. Samples may also be referred when an individual is stated to have had a previous episode of giardiasis or is immunocompromised. Testing is guided by the UK Standards for Microbiology Investigations (SMI) documentation of which there are three relating to parasite investigations (SMI B30, B31 and S7) [9]. Laboratories use this guidance to develop local testing algorithms to select appropriate samples for Giardia investigation. Despite increasing evidence that Giardia is acquired within the UK [10], an audit of Scottish NHS diagnostic microbiology laboratories found that, based on the UK SMI guidance, the majority of stools tested for Giardia were those from individuals who had recently travelled outside the UK [11]. This results in less than $20 \%$ of submitted stools being examined for Giardia. Use of commercial molecular or antigen-based assays have been reported to the permit screening of large numbers of stools for Giardia (and other gastrointestinal pathogens) [12-14]. Despite alternative methods being available, most Scottish NHS diagnostic microbiology laboratories use microscopy to detect Giardia [11]. These factors, combined with asymptomatic carriage, are likely to result in the significant under-ascertainment and under-reporting of cases [15].

This report raises awareness of Giardia by describing surveillance data captured for laboratory-confirmed cases of Giardia in Scotland over an 8-year period (2011-2018). At present, there is a drive for laboratories in the UK to move towards testing a wider selection of stools for Giardia and to implement sensitive, automated detection methods. These changes will greatly impact on the numbers of reported cases in Scotland in the future.

\section{Methods}

As Giardia is notifiable under the Public Health (Scotland) Act 2008, details of laboratory-confirmed cases were shared with NHS Health Protection Teams for follow-up and action [16]. This information was also shared with the Electronic Communication of Surveillance in Scotland (ECOSS) to Health Protection Scotland (HPS) for national surveillance. Reports of every laboratoryconfirmed case of giardiasis during 2011-2018 were collected from 21 NHS diagnostic microbiology laboratories within 14 territorial Scottish NHS health boards. At the time of data collection, all except one laboratory performed microscopy of wet mount preparations without the addition of stains to detect Giardia cysts and trophozoites. The exception was a laboratory in NHS Grampian that changed from performing microscopy to implementing an enzyme immunoassay (EIA) antigen detection method (Giardia/Cryptosporidium Combo EIA kit, IVD Research, Carlsbad, CA, USA) in 2015 [17].

Microsoft Excel and SPSS (version 21.0, SPSS, Inc., Chicago, IL, USA) were used for data analysis. The incidence of giardiasis was calculated per 100,000 by; NHS health board, age-band and sex over the eight-year period. The mean incidence per 100,000 in Scotland was also determined. In addition, incidence per 100,000 was calculated for NHS Grampian data in isolation for the 8-year period, as it was the only health board to test every stool for Giardia at the time of data analysis. Population data for calculating incidence was obtained from the National Records of Scotland mid-2018 population estimates in Scotland [18]. Seasonality was reported as the mean number of laboratory-confirmed cases rather than the incidence, as the population numbers for individual months were not available.

The Z-test was used to compare the differences in the mean incidence of giardiasis by sex and following a change in laboratory testing method in NHS Grampian. A probability $(P)$-value $<0.05$ was considered statistically significant. Whilst it is rare to receive more than one sample from an individual, an episode criterion of fourweeks was applied to ensure multiple samples from the same individual were only counted once.

\section{Results}

\section{Incidence by NHS Health Board}

Between 2011 and 2018, a total of 1631 cases were reported in Scotland (mean: 204; range: 166-269) with the lowest incidence reported during 2013 and 2014 (3.1 per 100,000) (Fig. 1). The highest incidence occurred during 2017 (4.9 per 100,000) (Fig. 1). The mean incidence over the 8-year period was 3.8 per 100,000 .

By individual NHS health board, Grampian, Borders and Lothian reported the highest incidence $(9.8,7.5$ and 
6.7 per 100,000, respectively; Fig. 2). Due to the small population size in Orkney, Shetland and the Western Isles, their high incidence of giardiasis should be viewed with caution.

\section{NHS Grampian}

Giardia reports from the NHS Grampian health board were examined further to explore the impact of changing the laboratory testing method during 2015 . The change from microscopy to the use of an EIA to screen every stool sample for Giardia resulted in a significant 3.6fold increase in the mean incidence of giardiasis from 4.2 (2011-2014) to $15.3(2015-2018)$ per $100,000(P=0.005$; Fig. 3).

\section{Age and sex distribution}

Overall, the incidence of giardiasis was significantly higher among males (mean 4.8 per 100,000) than females (mean 3.1 per 100,000$)(P<0.0001)$.

In males, incidence of giardiasis started high in the $0-4$ age group $(5.4$ per 100,000$)$ then decreased between the ages of 5-19 (Fig. 4). In the 20-24 years age group, the incidence increased sharply (7.7 per 100,000) and remained high then gradually declined from age 50 years onwards reaching an incidence of 2.6 per 100,000 by age 65 years and beyond (Fig. 4).
Incidence of giardiasis in females aged $0-4$ also began high $(3.7$ per 100,000$)$ then decreased between the ages of 5-19 (Fig. 4). Incidence rose gradually from age 20, peaking in the 35-39 age group (5.5 per 100,000) (Fig. 4). Thereafter, incidence declined in females except in those aged 60-64 years in which the incidence of giardiasis increased (4.0 per 100,000) (Fig. 4).

\section{Seasonality}

The number of laboratory-confirmed cases per month remained relatively stable throughout the 8-year period (mean 17 per month). The lowest mean number of cases was reported during February $(n=12)$ and the highest was reported during August $(n=26)$.

\section{Discussion}

The present data raise awareness of giardiasis by exploring the incidence in Scotland over an 8-year period. To our knowledge, this is the first Scottish report to describe a significantly higher incidence of giardiasis in males than females which merits further exploration. It also highlights preliminary findings to demonstrate the impact on the number of reported cases when sensitive, automated laboratory methods are applied.

The 3.6-fold increase in incidence within NHS Grampian during 2015-2018 was largely influenced by a

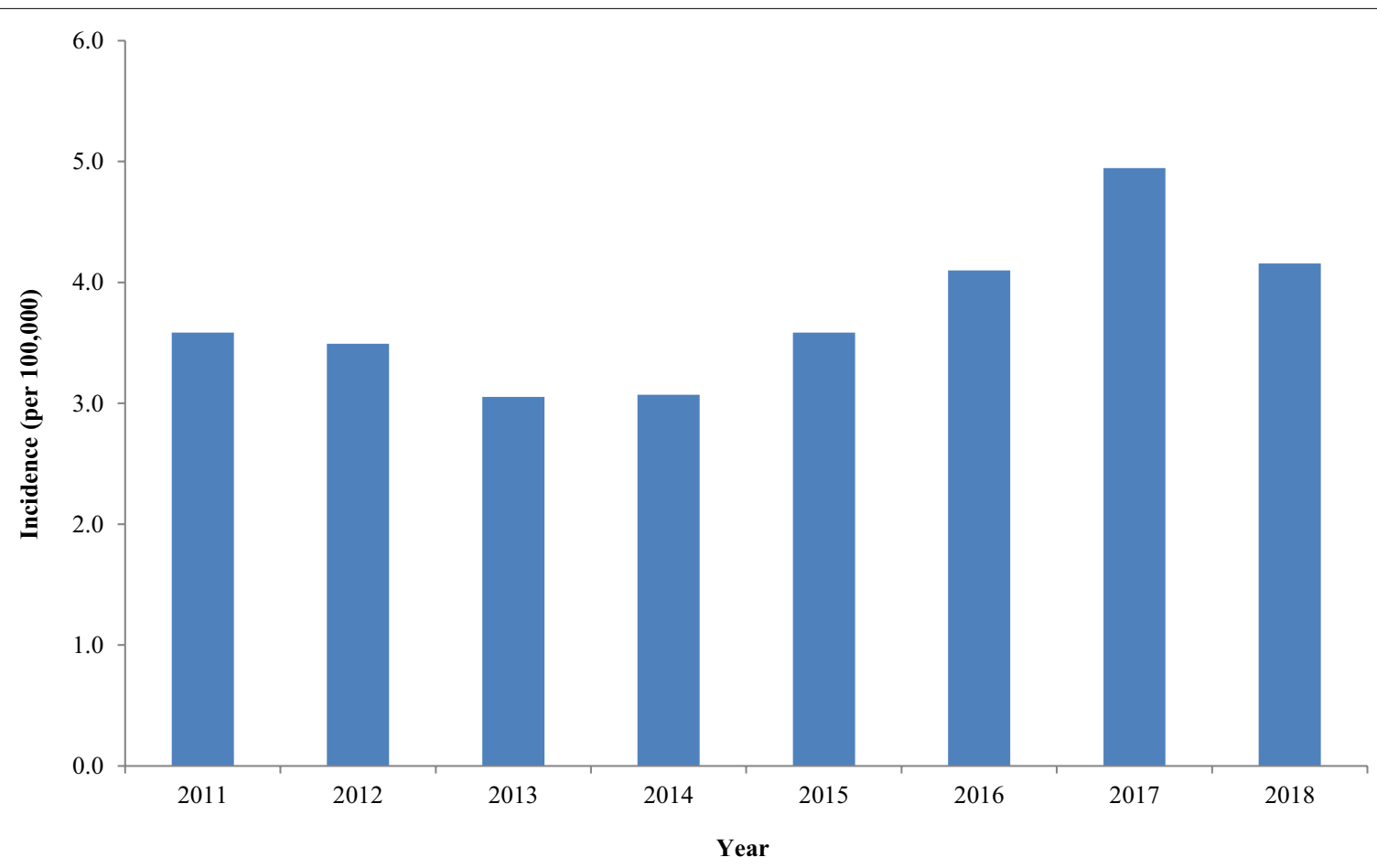

Fig. 1 Incidence of laboratory-confirmed giardiasis cases per 100,000 of the population in Scotland, 2011-2018 


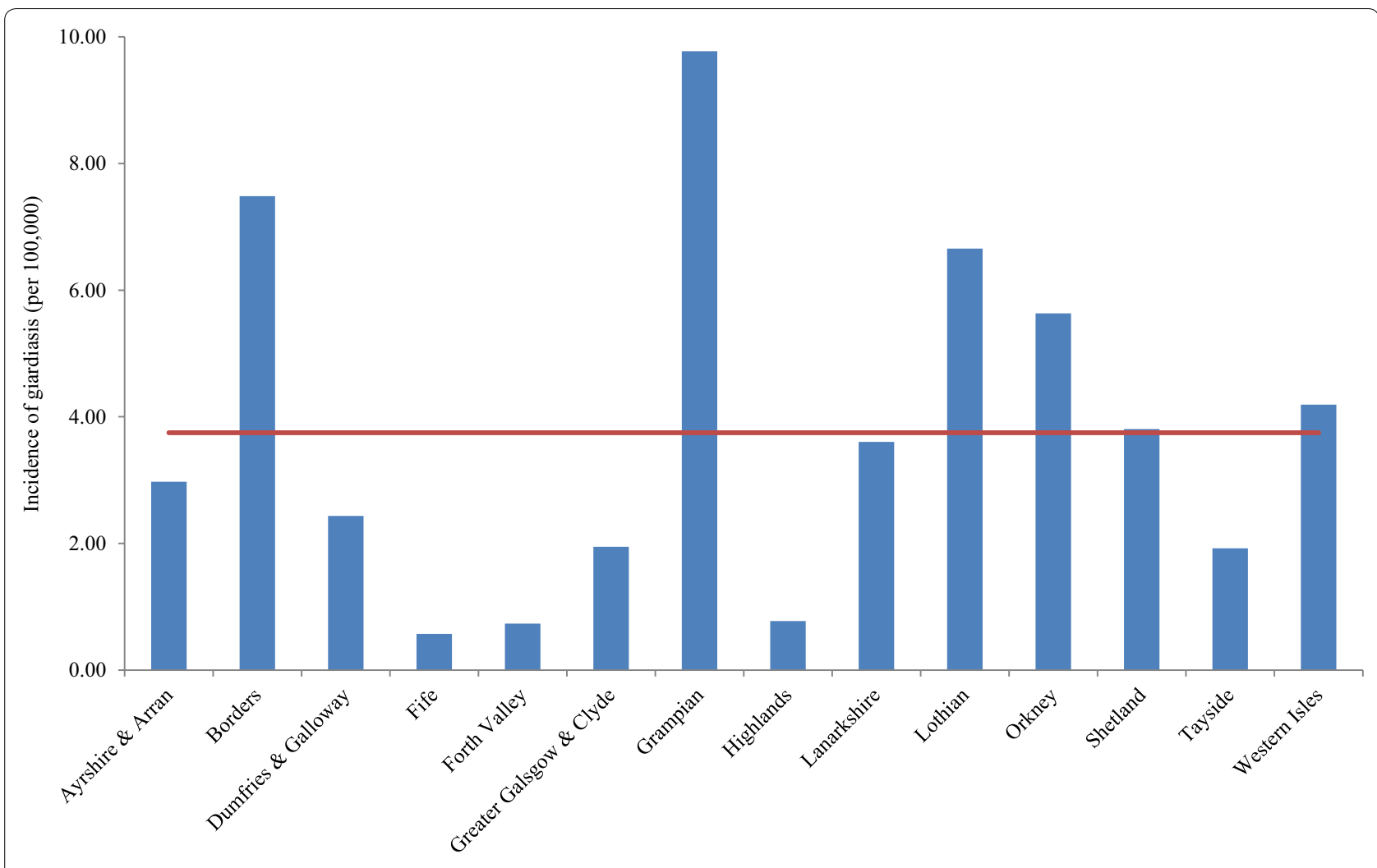

NHS Health Board Regions

Fig. 2 Incidence of laboratory-confirmed giardiasis cases per 100,000 of the population by NHS health board, 2011-2018. The solid line represents the mean incidence in Scotland

change in testing method within one laboratory. In 2015, antigen testing was introduced to replace microscopy. This permitted the screening of every submitted stool sample for Giardia. The data suggest that, in addition to Giardia being associated with travel outside the UK, it is also acquired locally. Further supportive evidence in the UK is described in a case-controlled study carried out in North-West England, where the authors highlight that as many as $75 \%$ of giardiasis cases were locally acquired [10]. As most Scottish laboratories currently use microscopy to detect Giardia and only test for it in $2-18 \%$ of submitted stools, it is highly likely that this pathogen is under-reported and many of the locally-acquired cases will go undiagnosed [11, 17]. The implementation of molecular testing for stool pathogens using assays including the BioFire FilmArray gastrointestinal panel (Biomerieux, Marcy l'Etoile, France), EntericBio Gastro Panel 2 (GP2; Serosep, Limerick, Ireland) and Luminex xTAG gastrointestinal pathogen panel (GPP; Luminex Corporation, Toronto, ON, Canada) is gradually being introduced across the UK and elsewhere [12, 13]. Molecular panels for the diagnosis of gastrointestinal parasites permit the rapid screening of a large number of stools for Giardia and reduce the need for microscopy expertise. However, molecular tests may not be cost-effective in every laboratory setting. In addition, deoxyribonucleic acid (DNA) may still be present soon after an infection has cleared and therefore, detection of DNA does not always represent an active current infection. Inhibitors may also be present in stools that impact on downstream molecular testing, which may lead to false negative results.

The exact reservoirs of Giardia in Scotland remain unclear. Of interest, rural and semi-rural areas in Scotland include the Borders and Grampian regions, which have the highest incidence of giardiasis. This coincides with having higher numbers of private water supplies than other regions and these are not subjected to strict monitoring procedures. Therefore, it is reasonable to suggest that individuals are at greater risk within these regions due to exposures from potentially contaminated water sources. In addition, grazing livestock within these $\mathrm{rural} / \mathrm{semi}$-rural regions may provide greater opportunities for acquiring infection through increased exposure to infective animal stools. Livestock and companion animals have been suggested as reservoirs as they share the same molecular types, known as assemblages, as 


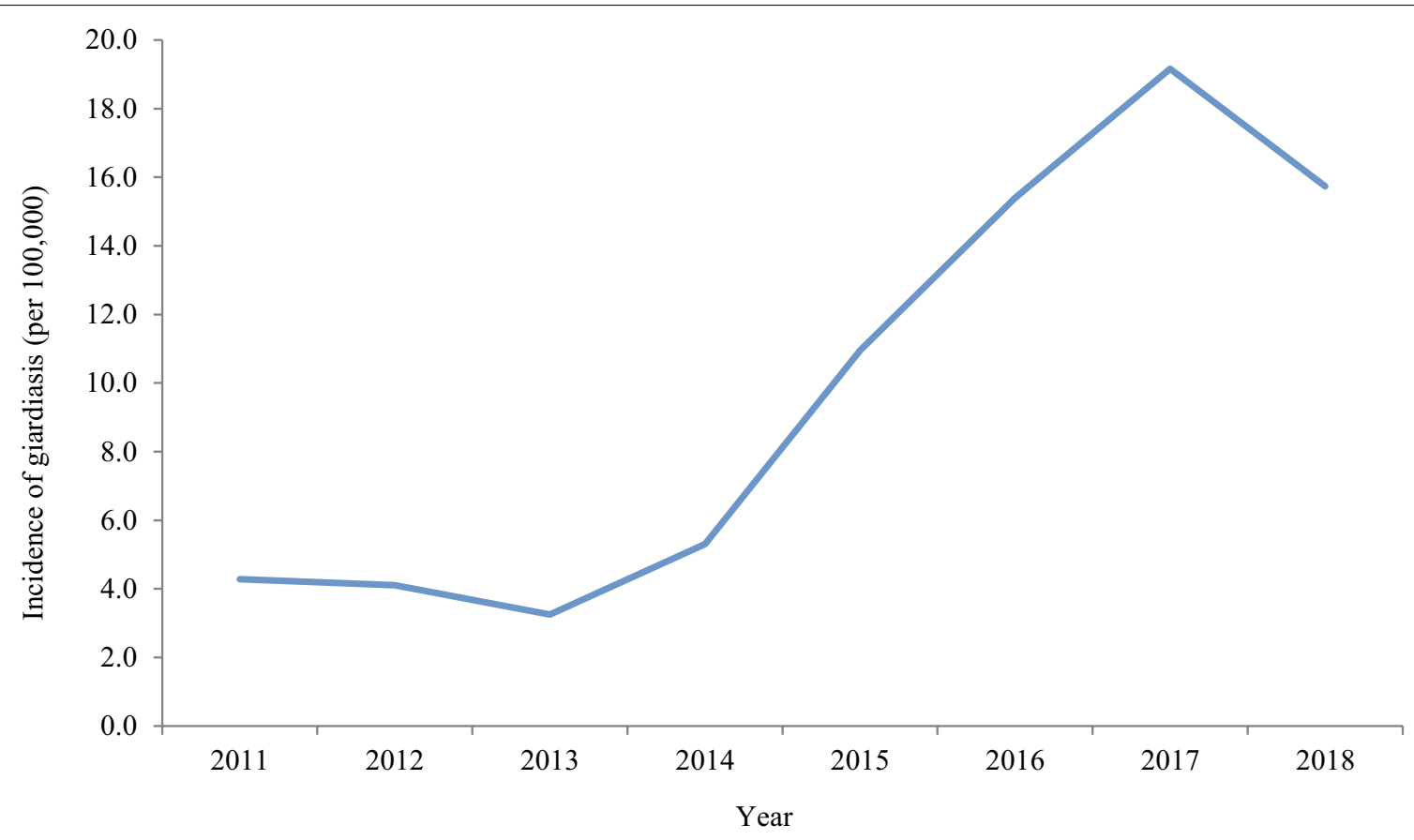

Fig. 3 Incidence of laboratory-confirmed giardiasis cases per 100,000 of the population within NHS Grampian, 2011-2018

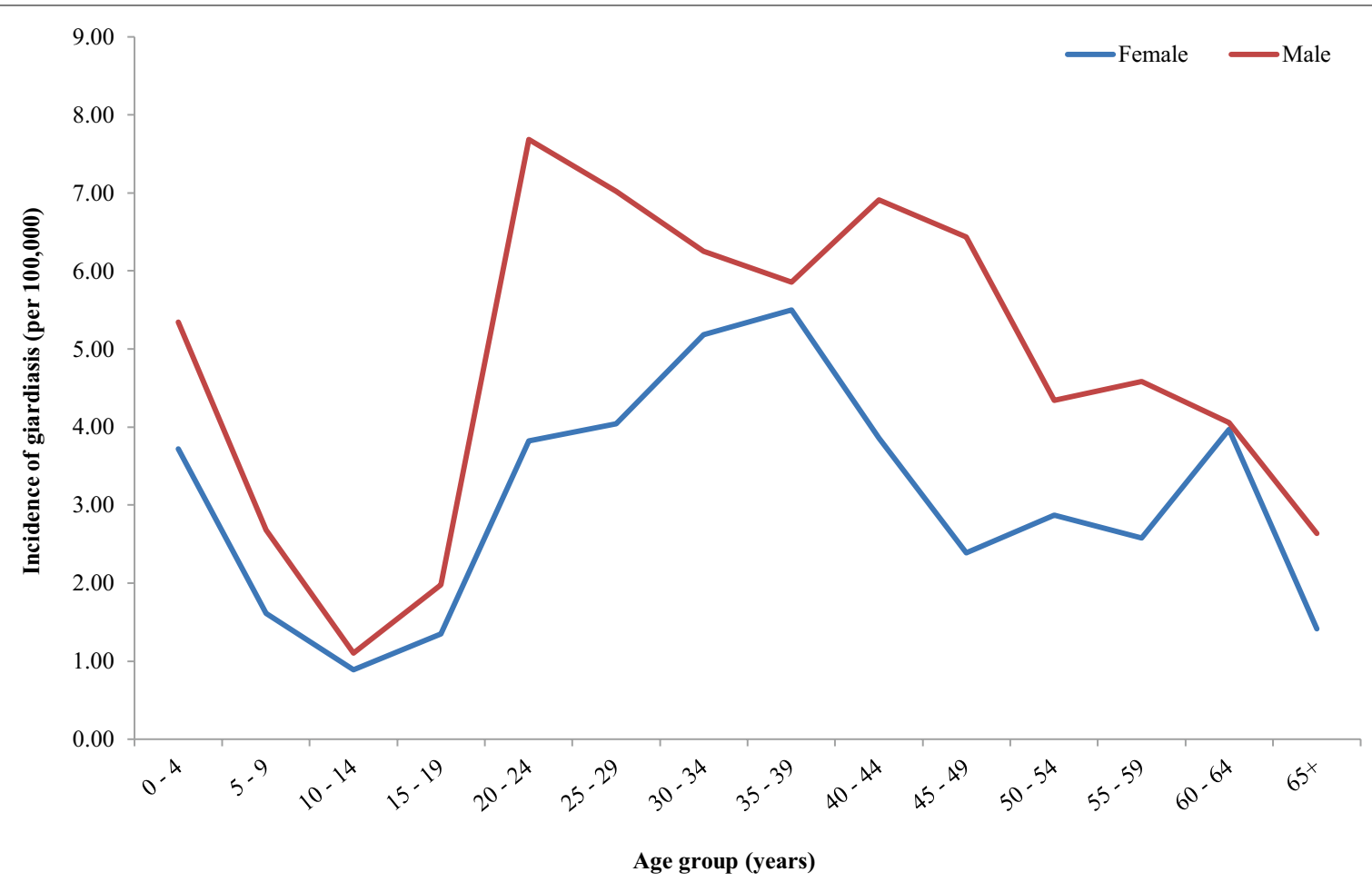

Fig. 4 Incidence of laboratory-confirmed giardiasis cases per 100,000 of the population in Scotland during 2011-2018 by age and sex group (NB: two reports were missing data on sex) 
those identified in humans (assemblages A and B). One UK study identified Giardia from 44\% (28/64) of sheep examined and from 33\% (93/283) of cattle [5]. However, assemblage $E$, which has not been identified in the human host, was found to be predominant. Despite these findings, assemblage A was also identified from $17 \%$ of sheep (4/24) and from $25 \%$ of cattle (16/63) in this study, suggesting the potential for zoonotic transmission. Data on companion animals in the UK are limited to one study on 878 dogs within kennels where mostly assemblages C and D were identified from 40 of the 41 samples that were genotyped, with only one sample found to be assemblage A [6]. In contrast, a Spanish study in dogs $(n=348)$, which included pet dogs within homes as well as dogs in kennels, found that $57 \%(20 / 35)$ of samples were either assemblage A, B or mixed (including A and/or B) infections [19]. To explore zoonotic potential further, robust in-depth molecular profiling is required to identify Giardia assemblages and how these relate to reported exposures from humans, companion animals, livestock, wildlife and the environment.

Unlike Cryptosporidium, a parasite which has welldescribed seasonal peaks occurring in spring and autumn [20, 21], Giardia numbers remain relatively constant throughout the year with an increase in August. However, due to the bias towards testing mostly travel-related samples, the difference is likely to reflect increased travel abroad and greater outdoor exposures during the warmer weather.

Incidence of giardiasis was highest in two age groups; 0-4 and 20-49 years-old, with a higher incidence reported in the latter group. Previously published Scottish surveillance data from 1988-2003 also showed a high incidence in young children ( $0-4$ years-old) and adults (20-39 years-old) [22]. However, in contrast, this earlier report described more cases within the 0-4 age group in comparison to the 20-39 age group, highlighting a shift across the years. The higher incidence in young children may reflect the healthcare seeking behaviour of parents and the increased sample submissions by clinicians. There are also likely to be a variety of other factors to explain this, including poorer hygiene behaviour in young children, the lack of previous exposure to Giardia, an immature immune system, increased exposure to recreational water, adoption from overseas and close contact with other children and family members. In one study that examined household contacts of infected individuals, having children under five years in the household was found to be a significant risk factor [15]. The authors also highlighted the presence of asymptomatic infection in 37 out of 41 infections identified from 212 household members. Therefore, transmission between adults and young children is likely to be underestimated.
Of interest, incidence of giardiasis in males was significantly higher than in females within every age group, particularly amongst adults. Sexual practices may account for spread within certain age groups and this has been reported in the MSM community [23]. However, this does not explain the higher incidence in other age groups. It has been suggested that females possess better hand hygiene practices and knowledge [24]. This, along with environmental exposures and/or occupational hazards, could contribute towards the higher incidence of giardiasis reported in males. This finding warrants further investigation as it may involve more complex gender factors.

\section{Conclusions}

How many giardiasis cases within Scotland and the rest of the UK go undetected remains unknown. Despite being identified within every Scottish NHS health board, the true number of symptomatic cases will only be revealed when all diagnostic laboratories progress to test every submitted stool for this pathogen. To support this, the implementation of sensitive, automated technologies within NHS diagnostic microbiology laboratories should be encouraged. By identifying travel-related and locally-acquired cases, clusters and outbreaks will be revealed that have previously gone undetected. Robust information to explain the gender bias and to define local reservoirs and transmission routes within Scotland is currently lacking. To address these points, the Scottish Health Protection Network (SHPN) has established an enhanced surveillance programme for Giardia to capture vital, in-depth information from individual cases within specific Scottish NHS health boards. This, combined with improvements to laboratory detection methods, better molecular tools for outbreak investigations and wider stool selection protocols, are absolutely essential to gain a better understanding of giardiasis. It is crucial individuals are tested and treated to prevent local and widespread outbreaks of this neglected pathogen.

\section{Abbreviations \\ NHS: National Health Services; HPS: Health Protection Scotland; ECOSS: electronic communication of surveillance in Scotland; IBS: irritable bowel syndrome; GPs: general practitioners; SMl: standards for microbiology investi- gations; EIA: enzyme immunoassay; MSM: men who have sex with men; SHPN: Scottish Health Protection Network.}

\section{Acknowledgements}

The authors would like to express their thanks to those Scottish Diagnostic Microbiology Laboratories for performing the testing and kindly providing the national data on each laboratory-confirmed case.

\section{Authors' contributions}

ASP provided and analysed the epidemiological data alongside LCF and CLA. LCF drafted the manuscript with input from CLA and ASP. All authors 
interpreted the epidemiological data. All authors read and approved the final manuscript.

\section{Funding}

This study received no specific grant from any funding agency, commercial or not-for-profit sectors.

\section{Availability of data and materials}

Data supporting the findings of this article are included within the article.

\section{Ethics approval and consent to participate}

This study retrospectively analyses laboratory reports collected as part of routine national surveillance for health protection purposes, and as such it is classified as 'usual practice' by the NHS Health Research Authority [25]. Therefore, ethical approval and research ethics committee review was not required, and informed consent was not obtained from participants in advance.

\section{Consent for publication}

Not applicable.

\section{Competing interests}

The authors declare that they have no competing interests.

\section{Author details}

1 Scottish Microbiology Reference Laboratories, Glasgow, Scotland, UK

${ }^{2}$ Health Protection Scotland, Glasgow, Scotland, UK.

Received: 27 September 2019 Accepted: 30 May 2020

Published online: 08 June 2020

\section{References}

1. Public Health England. Giardia data 2008 to 2017. 2018. https://www. gov.uk/government/publications/giardia-national-laboratory-data/giard ia-data-2008-to-2017\#giardia-data-2008-to-2017. Accessed 19 Mar 2020.

2. Wensaas K-A, Langeland N, Hanevik K, Mørch K, Eide GE, Rortveit G. Irritable bowel syndrome and chronic fatigue 3 years after acute giardiasis: historic cohort study. Gut. 2012;61:214-9.

3. Horton $\mathrm{B}$, Bridle $\mathrm{H}$, Alexander $\mathrm{CL}$, Katzer F. Giardia duodenalis in the UK: current knowledge of risk factors and public health implications. Parasitology. 2019;146:413-24.

4. Minetti C, Chalmers RM, Beeching NJ, Probert C, Lamden K. Giardiasis. BMJ. 2016;355:i5369.

5. Minetti C, Taweenan W, Hogg R, Featherstone C, Randle N, Latham SM, et al. Occurrence and diversity of Giardia duodenalis assemblages in livestock in the UK. Transbound Emerg Dis. 2014;61:e60-7.

6. Upjohn M, Cobb C, Monger J, Geurden T, Claerebout E, Fox M. Prevalence, molecular typing and risk factor analysis for Giardia duodenalis infections in dogs in a central London rescue shelter. Vet Parasitol. 2010;172:341-6.

7. Porter JDH, Gaffney C, Heymann D, Parkin W. Food-borne outbreak of Giardia lamblia. Am J Public Health. 1990;80:1259-60.

8. Nygård K, Schimmer B, Søbstad $\varnothing$, Walde A, Tveit I, Langeland N, et al. A large community outbreak of waterborne giardiasis-delayed detection in a non-endemic urban area. BMC Public Health. 2006:6:141.

9. Public Health England. Standards for microbiology investigations (UK SMI). n.d. https://www.gov.uk/government/collections/standards-formicrobiology-investigations-smi. Accessed 19 Mar 2020.

10. Minetti C, Lamden K, Durband C, Cheesbrough J, Platt K, Charlett A, et al. Case-control study of risk factors for sporadic giardiasis and parasite assemblages in north west England. J Clin Microbiol. 2015;53:3133-40.

11. Alexander CL, Currie S, Pollock K, Smith-Palmer A, Jones BL. An audit of Cryptosporidium and Giardia detection in Scottish National Health Service diagnostic microbiology laboratories. Epidemiol Infect. 2017;145:1584-90.

12. Khare R, Espy MJ, Cebelinski E, Boxrud D, Sloan LM, Cunningham SA, et al. Comparative evaluation of two commercial multiplex panels for detection of gastrointestinal pathogens by use of clinical stool specimens. J Clin Microbiol. 2014;52:3667-73.
13. McAuliffe G, Bissessor L, Williamson D, Moore S, Wilson J, Dufour M, et al. Use of the EntericBio Gastro Panel II in a diagnostic microbiology laboratory: challenges and opportunities. Pathology. 2017:49:419-22.

14. Batra R, Judd E, Eling J, Newsholme W, Goldenberg SD. Molecular detection of common intestinal parasites: a performance evaluation of the BD Max ${ }^{\mathrm{TM}}$ Enteric Parasite Panel. Eur J Clin Microbiol Infect Dis. 2016:35:1753-7.

15. Waldram A, Vivancos R, Hartley C, Lamden K. Prevalence of Giardia infection in households of Giardia cases and risk factors for household transmission. BMC Infect Dis. 2017;17:486.

16. Legislation.gov.uk. Public Health etc. (Scotland) Act 2008. n.d. http:// www.legislation.gov.uk/asp/2008/5/schedule/1. Accessed 19 Mar 2020.

17. Currie SL, Stephenson N, Palmer AS, Jones BL, Alexander CL. Underreporting giardiasis: time to consider the public health implications. Epidemiol Infect. 2017;145:3007-11.

18. National Records of Scotland. Mid-2018 population estimates Scotland. n.d. https://www.nrscotland.gov.uk/statistics-and-data/statistics/statistics -by-theme/population/population-estimates/mid-year-population-estim ates/mid-2018. Accessed 2 Sept 2019.

19. Adell-Aledón M, Köster PC, de Lucio A, Puente P, Hernández-de-Mingo $M$, Sánchez-Thevenet $P$, et al. Occurrence and molecular epidemiology of Giardia duodenalis infection in dog populations in eastern Spain. BMC Vet Res. 2018;14:26

20. Deshpande AP, Jones BL, Connelly L, Pollock KG, Brownlie S, Alexander CL. Molecular characterization of Cryptosporidium parvum isolates from human cryptosporidiosis cases in Scotland. Parasitology. 2015:142:318-25.

21. Deshpande A, Alexander CL, Coyne M, Brownlie S, Smith-Palmer A, Jones BL. Molecular diversity of Scottish Cryptosporidium hominis isolates. Epidemiol Infect. 2015;143:1219-24.

22. Pollock KGJ, Smith HV, Young D, Ramsay CN, Reilly WJ. Giardia surveillance in Scotland, 1988-2003. Eur J Clin Microbiol Infect Dis. 2005;24:571-3.

23. Mook P, Gardiner D, Kanagarajah S, Kerac M, Hughes G, Field N, et al. Use of gender distribution in routine surveillance data to detect potential transmission of gastrointestinal infections among men who have sex with men in England. Epidemiol Infect. 2018;146:1468-77.

24. Suen LKP, So ZYY, Yeung SKW, Lo KYK, Lam SC. Epidemiological investigation on hand hygiene knowledge and behaviour: a cross-sectional study on gender disparity. BMC Public Health. 2019;19:401.

25. Health Research Authority. HRA decision tools-defining research table 2017. http://www.hra-decisiontools.org.uk/research/docs/Defin ingResearchTable_Oct2017-1.pdf. Accessed 25 Sept 2019.

\section{Publisher's Note}

Springer Nature remains neutral with regard to jurisdictional claims in published maps and institutional affiliations.

Ready to submit your research? Choose BMC and benefit from

- fast, convenient online submission

- thorough peer review by experienced researchers in your field

- rapid publication on acceptance

- support for research data, including large and complex data types

- gold Open Access which fosters wider collaboration and increased citations

- maximum visibility for your research: over $100 \mathrm{M}$ website views per year

At BMC, research is always in progress.

Learn more biomedcentral.com/submissions 